\title{
Confirmation and Quantification of Genotoxic Impurity 2- Dimethylaminoethyl chloride hydrochloride (DMC HCl) by GCMS in Chlorpheniramine/Chlorphenamine Maleate
}

\author{
Prashant B. Zate ${ }^{1}$, Seema Kothari ${ }^{2}$, Manohar V. Lokhande ${ }^{3 *}$ \\ ${ }^{I}$ Research Scholar, Department of Chemistry, Pacific Academy of Higher Education \& Research University, \\ Udaipur-313003, Rajasthan, India \\ ${ }^{2}$ Department of Chemistry, Pacific Academy of Higher Education \& Research University, Udaipur-313003, \\ Rajasthan, India \\ ${ }^{3 *}$ Department of Chemistry, Sathaye College, Mumbai - 400057, Maharashtra, India
}

\begin{abstract}
The purpose of this research work is to develop a suitable GCMS method for the quantitative determination of Genotoxic impurity 2-Dimethylaminoethyl chloride hydrochloride (DMC HCl). The compound is inorganic and it is not easy to quantify at ppm level present in Chlorpheniramine/ Chlorphenamine Maleate Active Pharmaceutical Ingredients (APIs) with any other methods. Hence the GCMS method was developed on Thermo Scientific, WAXMS, $30 \mathrm{~m} \times 0.32 \mathrm{~mm} \times 0.25 \mu \mathrm{mcolumn}$ using Thermo Scientific Trace 1310 and TSQ at a flow rate of $1.0 \mathrm{~mL} / \mathrm{min}$. Under these conditions impurity was quantified by selecting mass range $40-700$ amu. The limit of detection and the limit of quantitation for the impurity were established. Validation of the developed GCMS method was carried out as per ICH requirements and the data shows that, the proposed method is specific, linear, accurate, precise and robust. This method has been tested in a number of Chlorpheniramine/ Chlorphenamine Maleate samples and used successfully for quantification of the impurity at ppm level. The developed GCMS method was found to be suitable to quantify the Genotoxic impurity 2-Dimethylaminoethyl chloride hydrochloride (DMC HCl) at ppm level present Chlorpheniramine/ Chlorphenamine Maleate.
\end{abstract}

Keywords: (GCMS), Genotoxic impurity; 2-Dimethylaminoethyl chloride hydrochloride (DMC HCl); Thermo Scientific, Chlorpheniramine/ Chlorphenamine Maleate; Threshold of Toxicological Concern (TTC).

\section{Introduction}

2-Dimethylaminoethyl chloride hydrochloride (DMC HCl)[1] is Process Impurity of Chlorpheniramine/ Chlorphenamine Maleate (Fig.1). 2-Dimethylaminoethyl chloride hydrochloride (DMC $\mathrm{HCl}$ ) shows presence of structural alert for genotoxic mutagenicity and carcinogenicity. The QSTR models predict the compound positive for genotoxicity, mutagenicity and carcinogenicity the compound is shown the positive for mutagenicity in training set used for Ames mutagenicity model [2-5].In genetics, Genotoxicity describes as property of chemical compound which may damage the genetic information within a cell leading mutations, which can lead to different types of Cancers in Human body in any forms.

While genotoxicity is often confused with mutagenicity, all mutagens are genotoxic; however, not all genotoxic substances are mutagenic. The alteration can have direct or indirect effects on the DNA: the induction of mutations, mistimed event activation and direct DNA damage leading to mutations. The permanent, heritable changes can affect either somatic cells of the organism or germ cells to be passed on to coming/future generations. Cells prevent expression of the genotoxic mutation by either DNA repair or apoptosis; however, the damage may not always be fixed leading to mutagenesis[4,5] Specifically, there is evidence that genotoxic substances may bind directly to DNA and may also act indirectly by affecting enzymes involved in DNA replication. There are three primary effects that Genotoxins can have on organisms by affecting their genetic information. Genotoxins can be carcinogens, or cancer-causing agents, mutagens, or mutation-causing agents, or teratogens, birth defect-causing agents [6]. The toxicological assessment of these genotoxic impurities and the determination of acceptable limits for such impurities in active substances is a difficult issue and not addressed in sufficient detail in the existing International Conference on Harmonization (ICH) Q3X guidelines [7]. The presence of trace level of the Genotoxic Impurity in drug substance or drug product is of genotoxicity concern and has been closely monitored by regulatory agencies and pharmaceutical industries [8]. The "threshold of toxicological concern' (TTC) of $1.5 \mu \mathrm{g} /$ person/day (exposure of genotoxic impurity in drugs that will be tested or dosed for longer than 12 months) has been suggested by the European Medicines Agency's (EMEA) "Guideline on the limits of genotoxic impurities" [9] and the Pharmaceutical Research and Manufacturers of America's (PhRMA) white paper [13]. Based on the TTC, the concentration limits of genotoxic impurity in drug substances or drug products can then be derived based on the maximum daily dose: concentration limit $(\mathrm{ppm})=$ 
$[1.5 \mu \mathrm{g} /$ day $)] /$ [dose (g/day)][2]. For a drug dosed at $1 \mathrm{~g}$ per day, for example, $1.5 \mathrm{ppm}$ would be the limit of a specific genotoxic impurity which would also be the 'target analyte level' (TAL) from an analytical perspective [7-9]. Given such a low ppm concentration limit, besides the control challenges in process chemistry, developing sensitive and robust methodology for their detection poses a tremendous analytical challenge for the pharmaceutical industry[10-15]. Therefore, potential genotoxins must be minimized during the synthesis the compounds and where there is difficulty achieving this, the method of manufactureshould preferably be changed 'As 2-Dimethylaminoethyl chloride hydrochloride $(\mathrm{DMC} \mathrm{HCl}$ ) is a genotoxic compound, the regulators may require the toxin levels to be controlled to $37.5 \mathrm{ppm}$ in the drug substance on the basis of Maximum Daily Dose of drug substance. The Quantification at such low level can be possible only by using GCMS or LCMS/MS and also there is no method for the quantification of this impurity hence a high sensitive GCMS method developed for the quantification of this genotoxic impurity 2-Dimethylaminoethyl chloride hydrochloride ( $\mathrm{DMC} \mathrm{HCl}$ ). The present trend in pharmaceutical analysis shows tremendous advancement in physio-chemical method of analysis for drugs which are very precise and accurate, the modern methods of choice involves sophisticated instruments like High performance liquid chromatography(HPLC), gas chromatography(GC), Mass spectrometry, Nuclear magnetic resonance spectroscopy(NMR)[16-17].

\section{Experimental}

Chemicals and reagents: The samples of Chlorpheniramine/Chlorphenamine maleate and 2Dimethylaminoethyl chloride hydrochloride (DMC HCl) (Fig. 2) were collected from Supriya Lifescience Ltd., Mumbai, Maharashtra, India. GCMS grade Dimethyl Sulfoxide was purchased from Advent, Mumbai, India.

Equipment: The GCMS method development and validation were done using Thermo Scientific Trace 1310 and TSQ 8000 Connected with Thermo Scientific mass detector GCMS system. The data were collected usingChromeleon ${ }^{\mathrm{TM}} 6.8$ Chromatography Data System (CDS) Software.

GCMS chromatographic conditions: The GC chromatographic separations were achieved on Thermo Scientific TRACETM 1310 Gas Chromatograph with TSQTM 8000 Evo Triple Quadrupole GCMS/MS. The GC was equipped with a capillary column (Thermo Scientific, TG-WAXMS, $30 \mathrm{~m} \times 0.32 \mathrm{~mm} \times$ $0.25 \mu \mathrm{m}$ ) and run in full-scan mode (scan range $40-700 \mathrm{~m} / \mathrm{z}$ with Detector voltage $2160 \mathrm{~V}$ ). Helium was employed as the carrier gas. The injector temperature was $250{ }^{\circ} \mathrm{C}$ and the initial oven temperature was $50{ }^{\circ} \mathrm{C}$, which was held for 5 minutes. The oven was ramped at $10^{\circ} \mathrm{C} / \mathrm{min}$ to $230^{\circ} \mathrm{C}$. The final temperature was held for 7 minutes for a total run time of 30.00 minutes. Three mass spectral libraries were used: an in-house library created using neat reference samples materials (OCME), the 2008 Scientific Working Group for the Analysis of Seized Drugs (SWGDRUG) library, and a combined Wiley and National Institute of Standards and Technology (NIST) library. Chromeleon ${ }^{\mathrm{TM}} 6.8$ Chromatography Data System (CDS) Software was used to quantitatively analyse the samples and qualifier ions were used to determine the presence and concentration of the analytes of interest.

Preparation of genotoxic impurity standard and test sample Solution: The stock solution of impurity standard prepared at approximately0.0375 mg/ml $(37.5 \mathrm{ppm})$ in dimethyl Sulfoxide. For linearity, the stock solution impurity was diluted using diluents to give standards at $0.23,0.47,0.94,1.87,3.75 \mathrm{ppm}$ with respect to test concentration. The testing API samples were typically prepared at approximately $100 \mathrm{mg} / \mathrm{mL}$ in dimethyl Sulfoxide.

\section{Result And Discussion}

Linearity: The linearity of 2-Dimethylaminoethyl chloride hydrochloride (DMC $\mathrm{HCl}$ ) was satisfactorily done. A series of solutions were prepared using 2-Dimethylaminoethyl chloride hydrochloride (DMC $\mathrm{HCl})$ at concentration levels from around quantification level to $150 \%$ and the concentration levels are 18.75, 30.00, $37.50,45.00,56.25 \mathrm{ppm}$ respectively. The peak area versus concentration data was done by linearity plot slope, intercept, and residual sum of squares analysis. The calibration curve was given based on response over the concentration range for 2-Dimethylaminoethyl chloride hydrochloride (DMC $\mathrm{HCl}$ ). The correlation coefficient2-Dimethylaminoethyl chloride hydrochloride (DMC $\mathrm{HCl}$ ) was 0.996 and the Linearity results are tabulated in table 1 and Fig.3.

Limit of Detection (LOD) and Limit of Quantitation (LOQ):The LOD and LOQ values of 2Dimethylaminoethyl chloride hydrochloride $(\mathrm{DMC} \mathrm{HCl})$ were predicted from the predication linearity data. Each predicted concentration was verified for precision by preparing the solutions at about predicted concentration and injecting each solution six times for GCMS/MS study and the predicted concentration for LOQ was 3.7 ppm and LOD was 0.94ppm (Fig.4 ABC \& D ) and the results are tabulated in table 2.

Precision: The precision of the developed method was checked by preparing solutions by spiking the impurity at $100 \%$ level with the drug substance for six times and injected each once also injected $100 \%$ spiked solution for 6 times to show the system precision. The \%relative standard deviation (RSD) of the areas at each level $5.3 \%$ and 13.21 confirming developed that method is précised. 
Accuracy: The accuracy of the method was evaluated in sample solutions were prepared in triplicate by spiking 2-Dimethylaminoethyl chloride hydrochloride (DMC $\mathrm{HCl}$ ) at LOQ level, 50\%, 100\% and 150\% with Chlorpheniramine/Chlorphenamine Maleate and injected each solution in to GCMS as per methodology. The percentage of recovery for the impurity was calculated and the values are 92.9\%, 93.1\%, 98.8\% and $101.4 \%$. At such low levels, these recoveries and \% relative standard deviation (RSD) were satisfactory and the results are tabulated in table 3 .

\section{Tables And Figures}

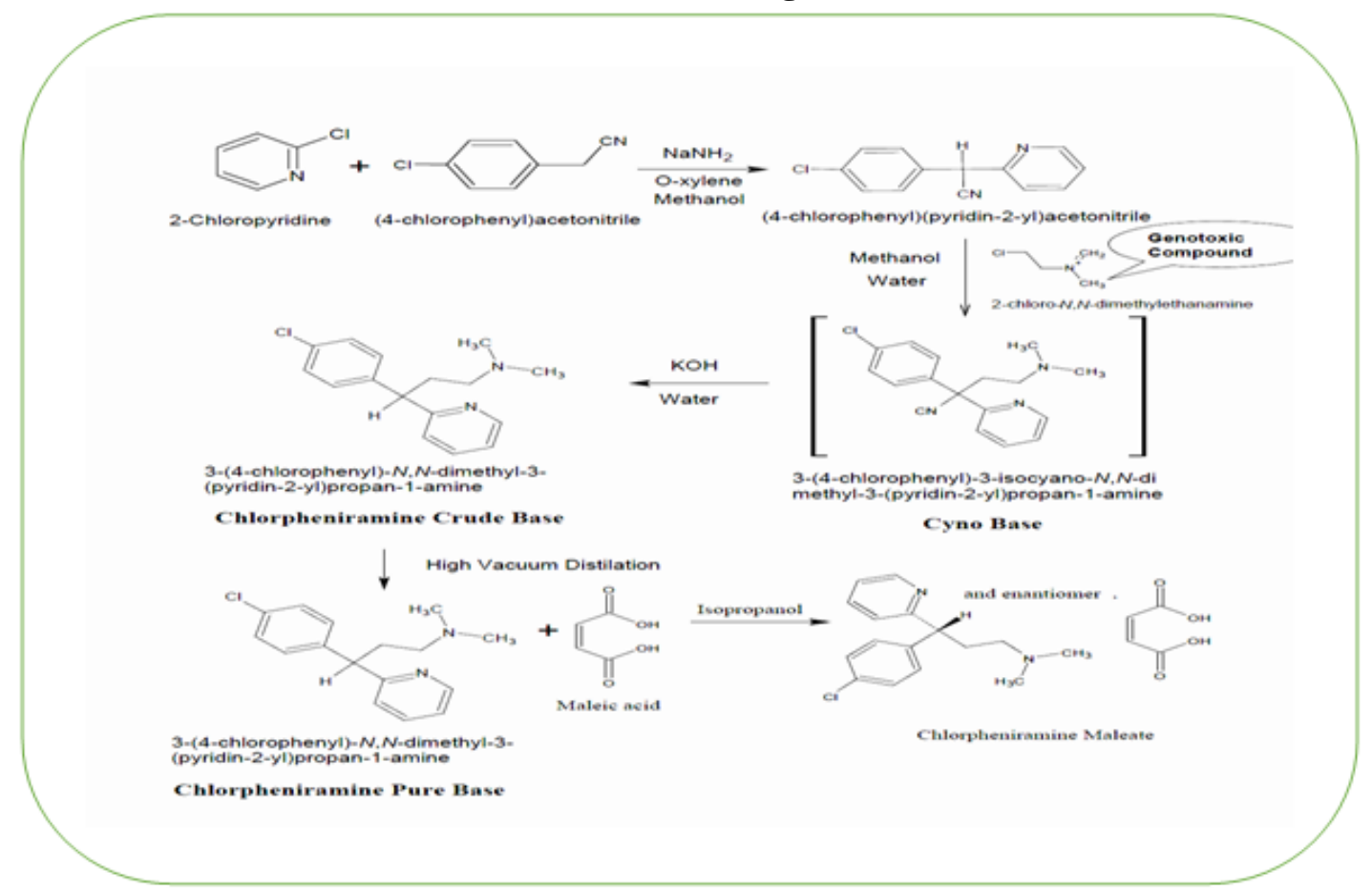

Fig. 1: Reaction Scheme of Chlorpheniramine Maleate.

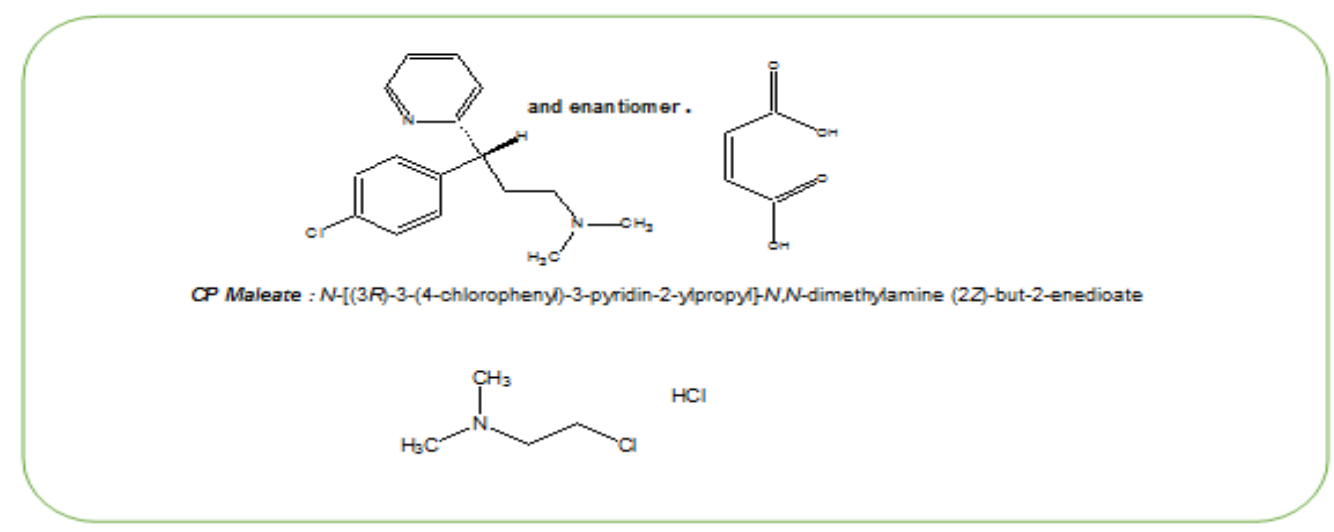

Fig. 2: Structures of Chlorpheniramine Maleate and $\mathrm{DMC} \mathrm{HCl}$ (its genotoxic impurity).

Table 1: The regression analysis data for $\mathrm{DMC} \mathrm{HCl}$

\begin{tabular}{|c|c|c|}
\hline Level & Conc. (ppm) & Mean Area \\
\hline 1 & 3.713 & 936638 \\
\hline 2 & 18.565 & 4365170 \\
\hline 3 & 29.704 & 8567094 \\
\hline 4 & 37.13 & 10829855 \\
\hline 5 & 44.556 & 13351036 \\
\hline 6 & 55.695 & 15695812 \\
\hline \multicolumn{2}{|r|}{ Slope } & 297028 \\
\hline \multicolumn{2}{|r|}{ Correlation } & 0.996 \\
\hline \multicolumn{2}{|r|}{ Intercept } & -416765.5 \\
\hline \multicolumn{2}{|r|}{ Intercept (\%) } & -3.64 \\
\hline \multicolumn{2}{|c|}{ Residual sum of squares } & 0.992572 \\
\hline
\end{tabular}




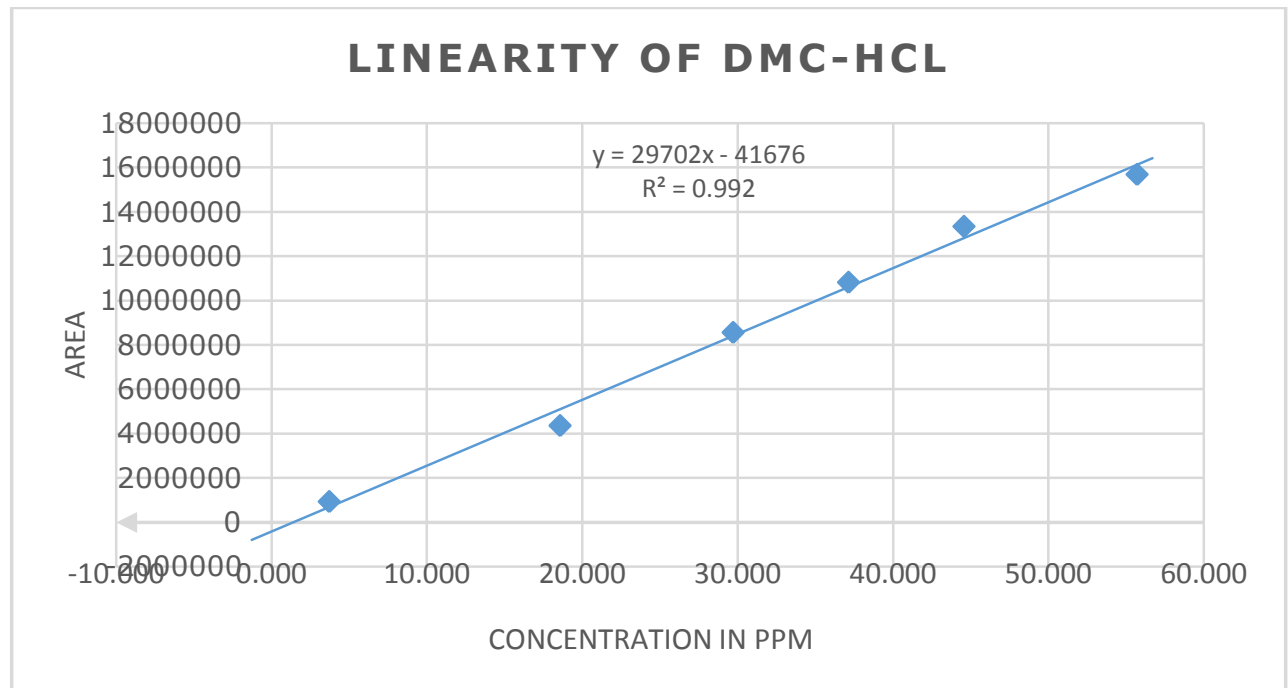

Fig.3: Regression line of DMC $\mathrm{HCl}$

Table 2: Table for LOQ Precision

\begin{tabular}{|c|c|}
\hline Injection & Area of DMC HCL (3.7 $\mathbf{~ p m )}$ \\
\hline 1 & 728611 \\
\hline 2 & 731306 \\
\hline 3 & 771110 \\
\hline 4 & 970365 \\
\hline 5 & 953198 \\
\hline 6 & 886350 \\
\hline Mean & $\mathbf{8 4 0 1 5 6 . 6 6}$ \\
\hline SD & $\mathbf{1 1 0 3 8 5 . 3 3}$ \\
\hline \%RSD & $\mathbf{1 3 . 1}$ \\
\hline
\end{tabular}

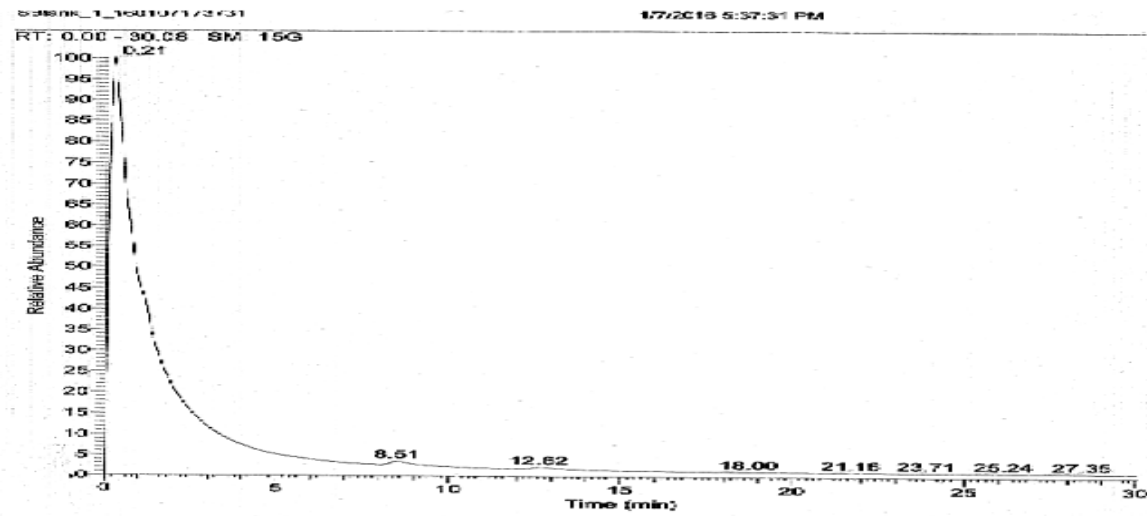

Fig.4A: Typical HPLC Chromatographs of Blank, Blank
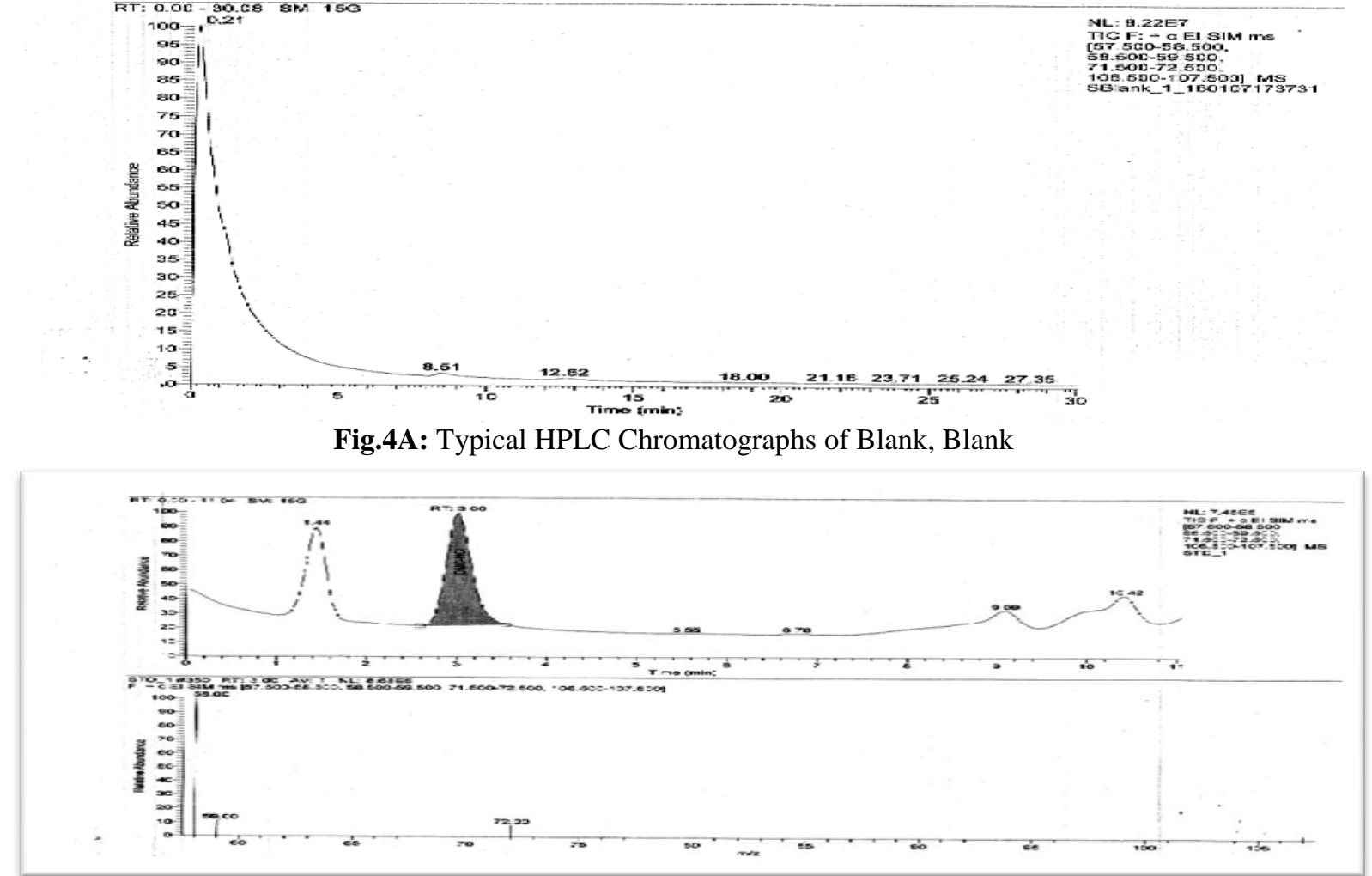

Fig. 4B: Typical HPLC Chromatographs of Blank, Standard 

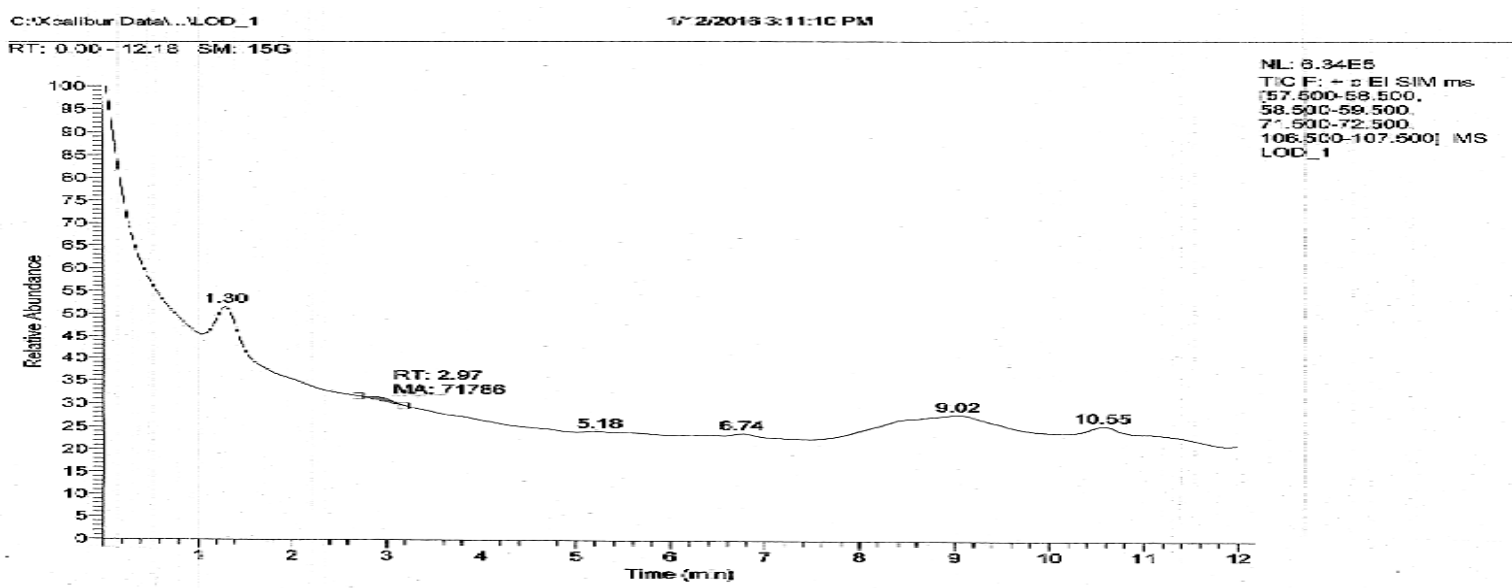

Fig. 4C: Typical HPLC Chromatographs of Blank, LOD

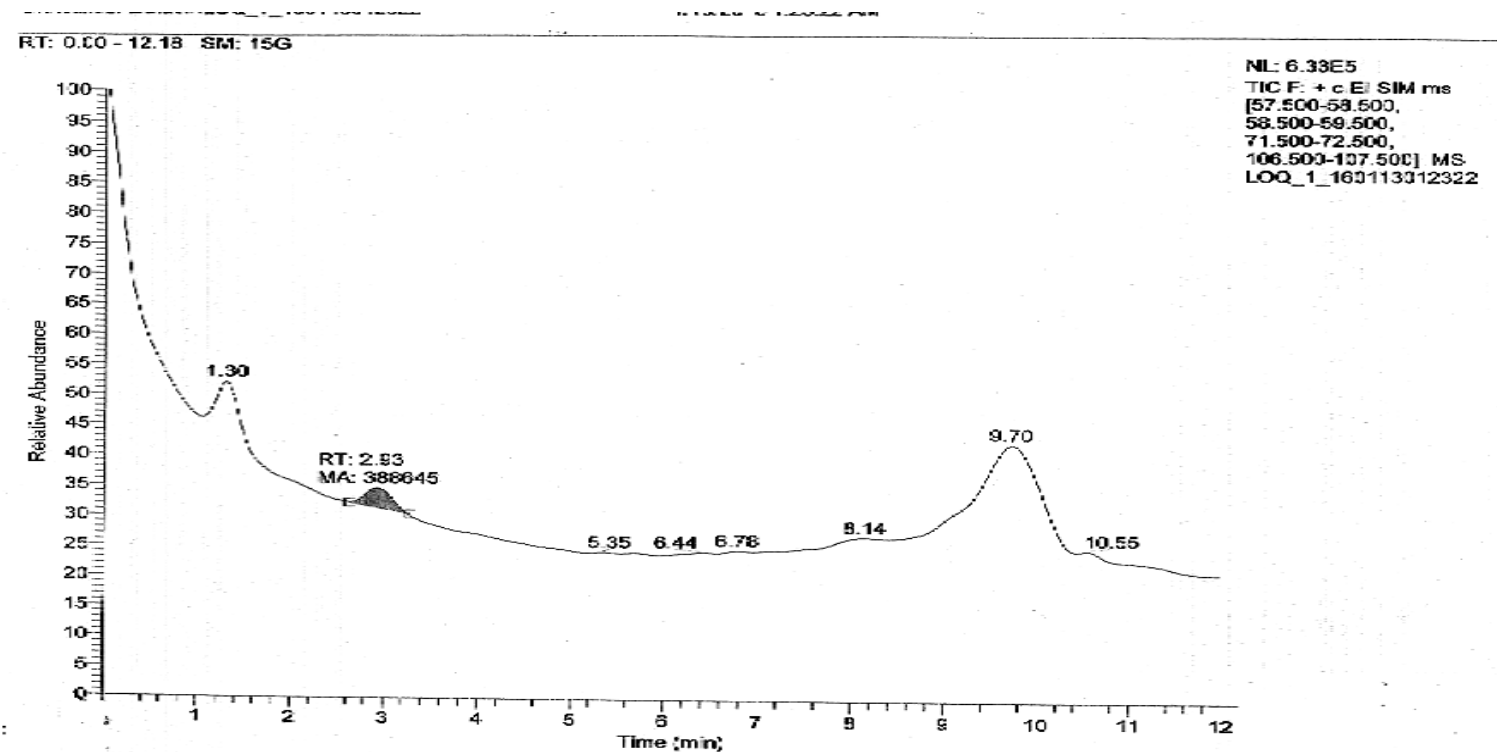

Fig. 4 D: Typical HPLC Chromatographs of LOQ

Table 3: \% recoveries found for spiked DMC $\mathrm{HCl}$ in Chlorpheniramine Maleate

\begin{tabular}{|c|c|c|c|c|c|c|c|}
\hline Level & $\begin{array}{c}\text { Qty. } \\
\text { Added } \\
\text { (ppm) }\end{array}$ & $\begin{array}{c}\text { Mean } \\
\text { Qty. } \\
\text { Added } \\
(\mathrm{ppm})\end{array}$ & Area & $\begin{array}{c}\text { Qty. Recovered } \\
\text { (ppm) }\end{array}$ & $\begin{array}{l}\text { Mean Qty. } \\
\text { Recovered } \\
\quad(\text { ppm) }\end{array}$ & \% Recovery & $\begin{array}{c}\text { Mean } \\
\text { \% Recovery }\end{array}$ \\
\hline LOQ-1 & 3.74 & \multirow{3}{*}{3.74} & 1129101 & 3.45 & \multirow{3}{*}{3.52} & 92.26 & \multirow{3}{*}{94.03} \\
\hline LOQ-2 & 3.74 & & 1136523 & 3.51 & & 93.85 & \\
\hline LOQ-3 & 3.74 & & 1228675 & 3.59 & & 95.99 & \\
\hline $50 \%-1$ & 18.68 & \multirow{3}{*}{18.68} & 6426461 & 17.12 & \multirow{3}{*}{17.39} & 91.65 & \multirow{3}{*}{94.01} \\
\hline $50 \%-2$ & 18.68 & & 7067019 & 18.83 & & 100.80 & \\
\hline $50 \%-3$ & 18.68 & & 6292017 & 16.92 & & 90.58 & \\
\hline $100 \%-1$ & 37.35 & \multirow{3}{*}{37.35} & 14044889 & 37.42 & \multirow{3}{*}{36.91} & 100.15 & \multirow{3}{*}{98.80} \\
\hline $100 \%-2$ & 37.35 & & 13709442 & 36.52 & & 97.78 & \\
\hline $100 \%-3$ & 37.35 & & 13807542 & 36.78 & & 98.47 & \\
\hline $150 \%-1$ & 56.03 & \multirow{3}{*}{56.03} & 20201040 & 53.82 & \multirow{3}{*}{54.80} & 96.06 & \multirow{3}{*}{97.81} \\
\hline $150 \%-2$ & 56.03 & & 20435043 & 54.44 & & 97.16 & \\
\hline $150 \%-3$ & 56.03 & & 21327091 & 56.15 & & 100.21 & \\
\hline & & & & & & $\begin{array}{c}\text { Mean } \\
\text { SD } \\
\% \text { RSD }\end{array}$ & $\begin{array}{l}96.16 \\
2.51 \\
2.61\end{array}$ \\
\hline
\end{tabular}

$\mathrm{SD}=$ Standard Deviation, $\mathrm{RSD}=$ Relative Standard Deviation 


\section{Conclusion}

On the basis of above study, reported method is sensitive specific, accurate, validated and well-defined GCMS/MS method for the Quantification of genotoxic impurity 2-Dimethylaminoethyl chloride hydrochloride $(\mathrm{DMC} \mathrm{HCl})$ at ppm level in Chlorpheniramine/Chlorphenamine maleate. The detection limit and quantification limit found to be $0.94 \mathrm{ppm}$ and $3.75 \mathrm{ppm}$ respectively. The described method is highly reliable technique for the quantification of the genotoxic impurity present in the Chlorpheniramine/Chlorphenamine maleateduring quality control testing.

\section{Acknowledgments}

The authors wish to thanks to the professors for supporting this research work. I would also like to thank colleagues of Promas Research Laboratories and Satish Wagh, MD, Shivani Wagh, Supriya Life Science Ltd, Mumbai for their cooperation and help to carry out this research work.

\section{References}

[1] 2-chloro-N, N-dimethylethanamine is reported to be genotoxic carcinogenic, Mutation Research, 297, 1993, 235-279.

[2] Safety Working Group, Questions and Answers on the Guideline on the Limits of Genotoxic Impurities, EMEA, (2008 \&2009), 21. EMA/CHMP/ SWP/431994/2007, EMEA, 2010.

[3] ICH M7, Assessment and Control of DNA Reactive (Mutagenic) Impurities in Pharmaceuticals to Limit Potential Carcinogenic Risk, Business Plan, 2010.

[4] L.S.Gold, C.B. Sawyer, R.Magaw, G.M.Backman, M. de Veciana, R. Levinson, A carcinogenic potency database of the standardized results of animal bioassays, Environ Health Perspect, 58, 1984, 9-319.

[5] K.L.Dobo, N. Greene, M.O.Cyro, S.Caron, W.W.Ku, WW, The application of structure-based assessment to support safety and chemistry diligence to manage genotoxic impurities in active pharmaceutical ingredients during drug development, RegTox Pharmacy, 44, 2007 282-293.

[6] N.G.Rathod, M.V.Lokhande, Characterisation and Identification of Process Related Impurity in Amodiaquine Hydrochloride by Using Some Analytical Techniques: A Review, American Journal of Advanced Drug Delivery, 3(5),2015, 264-284

[7] Genotoxicity, Validated Non-animal Alternatives, 2011 and 2013.

[8] ICH Q2 (R1), Validation of Analytical Procedures: Definitions and Methodology, 2005.

[9] US Food and Drug Administration (FDA), Food additives, Threshold of regulation for substances used in food-contact articles (final rule), Fed, Registration, 60, 36582-36596, 2005.

[10] M.B.V.Narayana, K.B. Chandrasekhar, B.M, Rao, Quantification of Genotoxic Impurity 4-Chloro-1-Hydroxy Butane Sulfonic Acid Sodium Salt by LCMS/ MS in Sumatriptan Succinate. Journal of Bioanalysis and Biomedical, 4, 2012, $104-107$.

[11] R. Kroes, A.G. Renwick, M. Cheeseman, J. Kleiner, I.Mangels Dorf, A.Preisman,, Structure-based threshold of toxicological concern (TTC): guidance for application to substances present at low levels in the diet, Food Chemical Toxicology, 42,2004, 65-83.

[12] J.Haginaka, C.Kagawa, Uniformly sized molecularly imprinted polymer for $d$-chlorpheniramine: Evaluation of retention and molecular recognition properties in an aqueous mobile phase, Journal of Chromatography A, 948, 2002, 77-84.

[13] L.Muller, R.J.Mauthe, C.M. Riley, M.M. Andino, D.De Antonis, C. Beels, A rationale for determining, testing, and controlling specific impurities in pharmaceuticals that possess potential for genotoxicity, RegTox Pharmacy, 44, 2006, $198-211$.

[14] H.Li, G.W.Sluggett, Development and validation of a sensitive GC-MS method for the determination of trace levels of an alkylating reagent in a betalactam active pharmaceutical ingredient. Journal of pharmacy and Biomedical analysis, 39, 2005, 486-494

[15] E.J.Delaney, An impact analysis of the application of the threshold of toxicological concern concept to pharmaceuticals. Regul Toxicol Pharmacology 49, 2008 107-124.

[16] M.K.Gupta, M.V.Lokhande, Structure Determination Of Impurity In Memantine Hydrochloride By Analytical Techniques , International Journal of General Medicine and Pharmacy, 3(4), 2014, 75-84.

[17] N.G.Rathod, M.V.Lokhande, Development and Characterisation of process related impurity in Hydralazine Hydrochloride by some analytical technique, Journal of Applicable Chemistry, 3 (5), 2014, 2011-2019.

IOSR Journal of Applied Chemistry (IOSR-JAC) is UGC approved Journal with S1. No. 4031, Journal no. 44190.

Manohar V.Lokhande. "Confirmation and Quantification of Genotoxic Impurity 2-Dimethylaminoethyl chloride hydrochloride (DMC $\mathrm{HCl}$ ) by GCMS in Chlorpheniramine/Chlorphenamine Maleate" IOSR Journal of Applied Chemistry (IOSR-JAC) 10.7 (2017): 21-26. 